\title{
FOREST DEVELOPMENT IN A RESTORED FLOODPLAIN: EFFECTS OF GRAZING, INUNDATION AND VEGETATION
}

\author{
PERRY CORNELISSEN ${ }^{1, *}$, MATHIEU DECUYPER ${ }^{2}$, \\ KARLÈ SÝKORA ${ }^{3}$, JAN BOKDAM 3 , and FRANK BERENDSE 3 \\ ${ }^{1}$ State Forestry Service, POB 2, 3800 AA, Amersfoort, the Netherlands \\ ${ }^{2}$ Forest Ecology and Forest Management Group, Wageningen University and Research, P.O. Box 47, 6700 AA, Wageningen, \\ the Netherlands \\ ${ }^{3}$ Nature Conservation and Plant Ecology Group, Wageningen University and Research, P.O. Box 47, 6700 AA, Wageningen, \\ the Netherlands \\ *Corresponding author: p.cornelissen@staatsbosbeheer.nl
}

\section{ABSTRACT}

In many countries worldwide, measures have been taken in floodplains for flood prevention and nature rehabilitation. In the Netherlands, floodplains are lowered by excavating in order to enlarge the discharge capacity and create opportunities for the development of river habitats such as forest. As forest can obstruct the flow of water through a floodplain, their development has to be controlled in some cases. In many floodplains, the growth of the vegetation is controlled by cattle and horses. We carried out an exclosure experiment over a twelveyear period in a partly excavated and year-round grazed floodplain along a lowland river in the Netherlands. We focussed on hawthorn (Crataegus monogyna Jacq.) as it plays an important role in the obstruction of water flow and in the wood-pasture cycle. Most hawthorn shrubs were recorded on the excavated part of the floodplain with a low cover of tall herbaceous plants. The total number of hawthorn plants was negatively related to inundation on the lower parts of the excavated sites and positively related to inundation on the higher parts of the excavated sites. The herbivores negatively affected the establishment and growth of hawthorn. Although lowering the floodplain by excavation will increase the discharge capacity of the floodplain in the short term, it will decrease in the long term as excavation also increases opportunities for the development floodplain forest. If flood prevention and nature rehabilitation are both goals to be achieved in a floodplain, hawthorn encroachment can be controlled by a clever design and management of grazing.

Keywords: cattle; Crataegus monogyna; floodplain forest; hawthorn; horses; wood-pasture hypothesis

\section{Introduction}

Natural large rivers are important for nature conservation because of their high biodiversity and their corridor function (e.g. Dynesius and Nilsson 1994; Naiman and Décamps 1997; Hughes et al. 2001; Tockner and Stanford 2002). Large rivers and their floodplains also have high economic value as they are used for shipping, agriculture, industrial activities, urbanization and recreation (e.g. De Waal et al. 1995; Naiman et al. 2002; Tockner and Stanford 2002). In the past few centuries, the large natural rivers and floodplains have dramatically changed due to the building of embankments, canalizations, dams, weirs, groynes, and reclamation of floodplains for agriculture (e.g. Dynesius and Nilsson 1994; Rosenberg et al. 2000; Tockner and Stanford 2002; Bunting et al. 2013). As a consequence, natural floodplains have become endangered landscapes, and many types of riverine habitats such as floodplain forests have become rare (e.g. Dynesius and Nilsson 1994; Brown et al. 1997; Olson and Dinerstein 1998; Tockner and Stanford 2002; Bunting et al. 2013). Restoration and conservation of these floodplain forests has become an important goal of river management (e.g. Brown et al. 1997; Leyer et al. 2012; Bunting et al. 2013).

However, floodplain forest can seriously obstruct water flow and reduce the discharge capacity of rivers, resulting in high flood water levels and associated safety risks (Makaske et al. 2011; Leyer et al. 2012). In order to achieve the safety goals, control of establishment and growth of woody species is sometimes needed. Especially of thorny shrubs such as hawthorn (C. monogyna), as they have the highest hydraulic roughness of the different types of floodplain vegetation (Van Velzen et al. 2003).

Hawthorn is a shrub or small tree, up to $10 \mathrm{~m}$, which is a common woody plant in Western and Central Europe. Hawthorn flowers (white, hermaphroditic, one style, 5-25 stamens) in April-June (Garcia and Chacoff 2007). Although the species is partially self-compatible, it relies on visits from insects to set fruit. It produces many single seeded fruits (red berries) in summer, which are ripe in September-October. The fruits are eaten by birds and mammals, which excrete the undigested seeds and spread the seeds (Herrera 1984; Snow and Snow 1988). To germinate, seeds need light and bare mineral soil as they do not establish in closed vegetation with a litter layer (Watt 1934; Smith 1980; Buttenschøn and Buttenschøn 1985). Hawthorn establishes on moist to dry sandy to clayey soils and can endure some inundation (Vreugdenhil et al. 2006). On its twigs and branches, Hawthorn produces thorns 1-3 cm long to protect itself from browsing by large herbivores (Gill 2006; Hester et al. 2006).

In many conservation areas in the Dutch floodplains, year-round grazing with low numbers of cattle and horses $(<0.4$ per ha; Kuiters et al. 2003) is used as a management tool to control the growth of vegetation. Some 
shrub and tree species such as Salix spp. or Populus spp. can easily be suppressed by large herbivores (Van Splunder 1998; Baraza et al. 2006; Cornelissen et al. 2014a, 2014b), but others, like hawthorn, are relatively resistant to grazing because of its thorns (Gill 2006; Hester et al. 2006). Because of their physical defence, hawthorn and other thorny shrubs also play an important role in the woodland-grassland cycle of the wood-pasture hypothesis of Vera (2000). According to this hypothesis, large herbivores are responsible for the development of park-like landscapes. They contribute to the transition of woodland to grassland by debarking trees, maintain short grazed grasslands and create opportunities for the re-establishment of thorny shrubs in these grazed grasslands. Once established in grazed grasslands, hawthorn can serve as refugium by protecting other, more palatable tree species (Baraza et al. 2006; Gill 2006) and initiate forest development.

In order to optimize both safety and ecological values, it is important to monitor encroachment by woody plants after measures taken to restore safety and ecology are realized and grazing has started. In general, establishment and growth of shrubs and trees on floodplains largely depend on flooding, substrate, light and root competition with grasses and tall herbaceous plants, and herbivores, especially during the early life stages of the woody species (Jones et al. 1989; Streng et al. 1989; Siebel 1998; Van Splunder 1998; Hughes et al. 2001; Vreugdenhil et al. 2006).

In order to understand the effect of grazing, inundation and vegetation on the encroachment by woody plants, we carried out an exclosure experiment over a twelve-year period in a restored and year-round grazed floodplain along the river Waal in the Netherlands. We focused on hawthorn because of its high flow resistance and its role in the wood-pasture hypothesis. This shrub is less flood tolerant than softwood species (Vreugdenhil et al. 2006). Hawthorn germinates on bare soil and in grazed grasslands, but survival of seedlings is low in shaded environments (Watt 1934). Hawthorn can resist grazing pressure better than non-thorny softwood species (Good et al. 1990; Baraza et al. 2006). We expected that: (1) in the excavated areas with bare sandy soils and low cover of tall herbaceous plants, more hawthorn would become established than in the non-excavated, vegetated areas with high cover of tall herbaceous plants; (2) establishment of hawthorn is negatively related to inundation; (3) cattle and horses affect the establishment and growth of hawthorn; (4) in the grazed grasslands there will be more hawthorn than in the ungrazed grasslands.

\section{Material and Methods}

\section{Study area}

This study was carried out on the floodplain Afferdense and Deestse Waarden (51 $53^{\circ} 44^{\prime \prime} \mathrm{N}$; $\left.5^{\circ} 37^{\prime} 40^{\prime \prime} \mathrm{E}\right)$ along the river Waal in the Netherlands. The study area was approximately 46 ha. In 1996, 23 ha of this area, originally covered with grasslands, were excavated and the first section of a new side channel was dug within the lowered floodplain to increase the discharge capacity and create opportunities for the development of nature (Fig. 1).

The unexcavated parts of the study area consisted of nutrient rich clayey soils and the excavated parts of nutrient poor sandy soils (Table 1). Water levels of the river Waal at the study area varied within and among years (Fig. 2). High levels were recorded during winter and low levels during summer. Average water levels were higher during 1999-2003 and lower during 1996-1998 and 2003-2007.

On nutrient-rich soil the vegetation consisted mainly of short grasslands (e.g. Lolium perenne L., Poa trivialis L., Festuca rubra L., Trifolium repens L., Potentilla reptans L., Taraxacum spp., Cirsium arvense (L.) Scop., Urtica di-

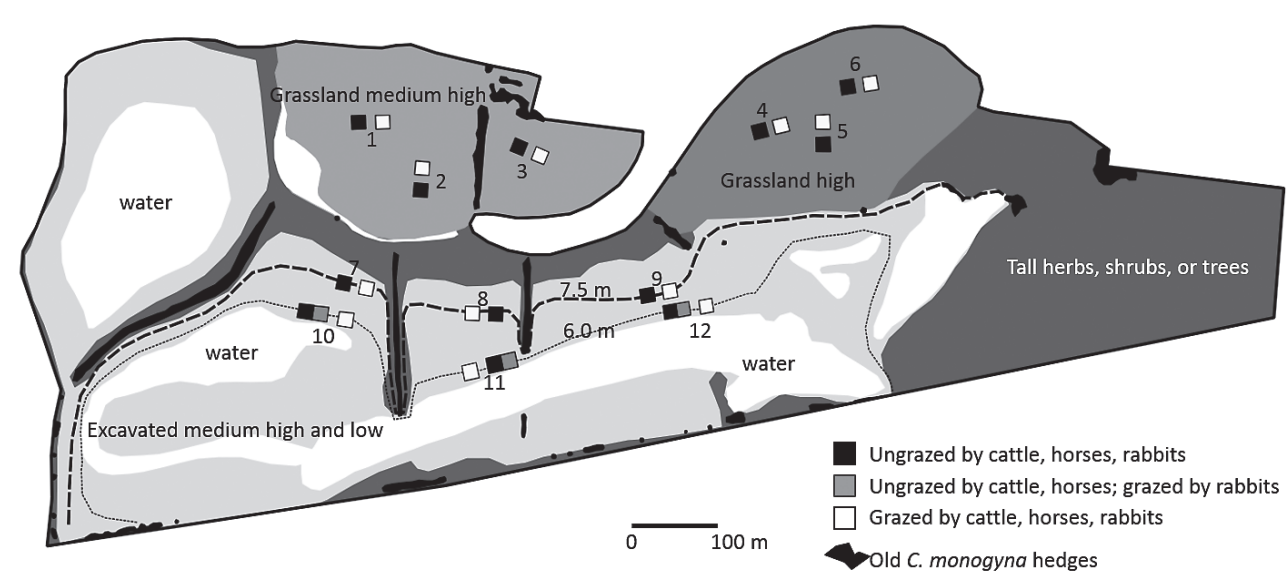

Fig. 1 Location of the strata grassland high, grassland medium high, excavated medium high, excavated low, and blocks (nr 1-12) in the study area. The blocks consist of grazed and ungrazed plots indicated by the black, grey and white squares. The dashed lines in the excavated part of the floodplain indicate the elevation levels of $6.0 \mathrm{~m}$ (low) and $7.5 \mathrm{~m}$ (medium high) + NAP. 
Table 1 Characteristics strata study area. Inundation characteristics are averages and standard errors of mean (within parentheses) over the period 1996-2007. NAP is the Dutch reference level for elevation, which is about sea level. January-December and March-October indicate the period from January to December and from March to October.

\begin{tabular}{|c|c|c|c|c|c|}
\hline & & \multicolumn{4}{|c|}{ Strata } \\
\hline & & \multicolumn{2}{|c|}{ Not excavated } & \multicolumn{2}{|c|}{ Excavated } \\
\hline & & High & Medium high & Medium high & Low \\
\hline \multicolumn{2}{|l|}{ Vegetation 1996} & Grassland & Grassland & Bare soil & Bare soil \\
\hline \multicolumn{2}{|l|}{ Soil (\% lutum $(<2 \mu \mathrm{m}))$} & 26 & 25 & 4 & 3 \\
\hline \multicolumn{2}{|l|}{ Ground level ( $m+$ NAP) } & 9.0 & 7.5 & 7.5 & 6.0 \\
\hline Total inundation (days) & January-December & $7(2)$ & $27(6)$ & $27(6)$ & $83(13)$ \\
\hline \multirow{2}{*}{ Inundation frequency $(\mathrm{N})$} & March-October & $3(1)$ & $12(4)$ & $12(4)$ & $42(10)$ \\
\hline & January-December & $1(<1)$ & $3(1)$ & $3(1)$ & $7(1)$ \\
\hline \multirow{2}{*}{ Average length of inundation events (days) } & March-October & $1(<1)$ & $1(<1)$ & $1(<1)$ & $4(1)$ \\
\hline & January-December & $5(1)$ & $8(1)$ & $8(1)$ & $14(2)$ \\
\hline \multirow{3}{*}{ Average water depth during inundation $(\mathrm{cm})$} & March-October & $3(1)$ & $5(1)$ & $5(1)$ & $12(3)$ \\
\hline & January-December & $16(6)$ & $93(11)$ & $93(11)$ & $115(9)$ \\
\hline & March-October & $5(4)$ & $65(15)$ & $65(15)$ & $88(12)$ \\
\hline
\end{tabular}

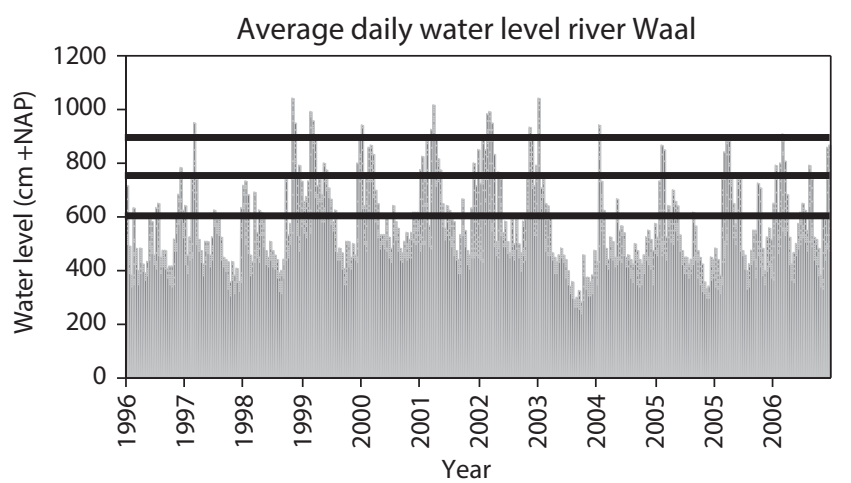

Fig. 2 Average daily water level of the river Waal at Afferdense and Deestse Waarden. The horizontal lines show the surface levels of the different strata of $6.0,7.5$ and $9.0 \mathrm{~m}+$ NAP.

oica L.; 12 ha), and a mosaic of tall herbaceous plants, tall grasses and willows (e.g. C. arvense, U. dioica, Symphytum officinale L., Phalaris arundiancea, L. Glyceria maxima (Hartm.) Holmb., Salix spp.; 11 ha). In the excavated areas, vegetation was almost absent during the first year. In the second year, pioneer species (e.g. Chenopodium album L., Erigeron canadensis (L.) Cronq., Matricaria maritima (L.) W.D.J.Koch, Rumex maritimus L.) colonized the area. Within the study area, some old hawthorn shrubs and hedges were present. These were remnants of the former agricultural landscape.

Before 1996, the study area was grazed by high numbers (1-2 animals/ha) of dairy cattle, and parts of the grassland that were invaded by tall herbaceous plants such as C. arvense or U. dioica, were mown. After 1996, the study area was grazed during summer (April-November) by privately owned cattle (c. 15 cows) and horses (c. 20 mares). During winter (November-March), the owner moved the cattle to the farm for supplementary feeding and shelter, but the horses remained in the area.
The horses did not get supplementary feeding and the grasslands were not mown anymore.

\section{Exclosure experiment}

We carried out an exclosure experiment to determine the effects of herbivores, vegetation and inundation on establishment and growth of woody species. The experiment consisted of 12 blocks (i.e. experimental unit; Hurlbert 1984) to test the effect of herbivores. Each block consisted of an ungrazed (exclosure) and a grazed plot (both $15 \times 15 \mathrm{~m}$ ). The grazed plot was randomly placed at a distance of $10 \mathrm{~m}$ from the exclosure. All exclosures were made to exclude not only cattle and horses but also small herbivores such as rabbits and hares.

Based on ground level and excavation, we distinguished four different strata: (1) excavated low; (2) excavated medium high; (3) grassland medium high; (4) grassland high (Fig. 1, Table 1). The strata grassland low and excavated high were not present in the study area. Although the strata are not replicated, as replication was not possible at this scale, we used these strata in our experiment to determine the effects of inundation and vegetation, next to herbivores, on the establishment and growth of woody species on this floodplain. To describe the effect of excavation and grazing by all herbivores on vegetation and hawthorn, we compared the stratum grassland medium high with excavated medium high. To determine the effect of inundation and grazing by all herbivores on vegetation and hawthorn, we compared the stratum excavated medium high with excavated low. The stratum grassland high was not used in these tests as no hawthorn became established on this stratum. To analyse these effects, in each stratum 3 blocks were randomly placed after the excavation in the summer of 1996.

In the stratum "excavated low", we expected the establishment of high numbers of Salix spp. and a rapid in- 
crease in cover and height of these species immediately after excavation (Van Splunder 1998). To investigate the effect of small herbivores on these fast colonizing, palatable softwood species, we added an extra exclosure to the blocks in this stratum, excluding only cattle and horses.

For describing the results, we used the following codes for the strata:

\begin{tabular}{|l|c|c|}
\hline & Grassland & Excavated \\
\hline High (9.0 m NAP) & GH & \\
\hline Medium low (7.5 m NAP) & GM & EM \\
\hline Low (6.0 m NAP) & & EL \\
\hline
\end{tabular}

To distinguish between grazed and ungrazed sites within the strata, we added to these codes the letter -g or $-\mathrm{u}$, respectively.

\section{Inundation}

River water level data were obtained from the Ministry of Infrastructure and Water management. We determined total number of days with inundation, number of inundation events (frequency), average length of inundation events and average water depth during inundation as they explained most of the variation in establishment and growth in other studies (e.g. Siebel 1998; Van Splunder 1998; Vreugdenhil et al. 2006). We also distinguished two periods of inundation: 1) from January to December and 2) from March to October (growing season).

\section{Herbivore numbers and daily energy expenditure}

The number of cattle and horses stayed the same over the years from 1996 to 2007 (see section study area). We counted the numbers of hares and rabbits during evenings in winter (December-January) using a light. In 1997, 1999 and 2007, eight counts per winter were carried out along a fixed route through the whole of the area studied. There were no roe deer (Capreolus capreolus L.) or beaver (Castor fiber L.) on this flood plain (pers. comm. State Forestry Service).

To compare the effect of grazing by large and small herbivores and to compare our results with that of others (e.g. Bakker et al. 2004), we transformed herbivore densities into daily energy expenditure (DEE). According to Bakker et al. (2004), the amount of energy an average animal spends daily is two times its basal metabolic rate (BMR): $\mathrm{DEE}=2 \times 2930 \times \mathrm{W}^{0.75} \mathrm{~kJ}$ per day. For cows and mares of different ages (1-15 years old) we assumed an average weight of $350 \mathrm{~kg}$ based on Cornelissen et al. (1995), for rabbits we used an average weight of $1.5 \mathrm{~kg}$ (Wallage-Drees 1988) and for hares $4 \mathrm{~kg}$ (Lange et al. 1994).

\section{Vegetation surveys}

In August 1997, 1999, 2001 and 2007, we assessed vegetation cover and height of two structural layers: (1) low grasses and low herbaceous plants; (2) tall herbaceous plants. We established four permanent quadrats of $2 \times$
$2 \mathrm{~m}$ within the ungrazed plot at $2 \mathrm{~m}$ distance from the fence of the exclosure, and in the same way within the grazed plot. Cover was estimated (vertical projection on the ground in percentages) and height was measured with a ruler and a polystyrene disk (radius $50 \mathrm{~cm}$, weight $320 \mathrm{~g}$ ), which was lowered over a ruler on to the sward. Average cover and height were calculated for each ungrazed and grazed plot. These averages were used to calculate averages and standard errors of cover and height of grazed and ungrazed vegetation for each stratum.

In August 2007, cover and height of all woody species were assessed in the total area $(15 \times 15 \mathrm{~m})$ of the ungrazed and grazed plots. Cover was estimated visually as a percentage of the area of ground occupied. Heights of woody plants were measured with a ruler. The measurements per ungrazed and grazed plot were used to calculate averages and standard errors of cover and height of woody species in grazed and ungrazed plots per stratum.

In November 2007, all hawthorn plants present in the ungrazed and grazed plots were harvested for age determination in order to investigate the effect of inundation, vegetation and grazing on establishment and growth. Height, crown diameter (mean of maximum and minimum diameter), stem circumference and total number of twigs (up to $2 \mathrm{~m}$ height) were measured before the destructive harvest. Circumference was later transformed into an average stem diameter, as it is an important parameter for determining the hydraulic roughness of the shrub.

The nomenclature used for plant species follows that of Van der Meijden (2005).

\section{Age determinations of hawthorn}

Age determination of hawthorn was based on growth rings and was carried out as described by Decuyper et al. (2014).

\section{Statistical analysis}

We used Generalized Linear Models with a Poisson distribution and a log-link function to test the effects of ground level (medium high or low), excavation (yes or no) and herbivores (yes or no) on total number of hawthorn present in 2007; this revealed no over dispersion. We also nested block within excavation or ground level to correct for possible random variation among blocks.

To test the effect of grazing by rabbits on the total number of hawthorn present in 2007, we compared the ungrazed and grazed plots in the stratum excavated low. We used Generalized Linear Models with a negative binomial distribution and a log-link function to test these effects because of over dispersion. Grazing (yes or no) was used as predictor. Block was also incorporated to correct for possible random variation among blocks.

General Linear Model Repeated Measures was used to test the effects of excavation or ground level, herbivores (between-subjects factors) and year (within-subjects factor) on the dependent variables cover and height 
of low grasses and herbaceous plants and tall herbaceous plants. We nested block within excavation or ground level to correct for possible random variation among blocks. To meet the assumptions of the statistical test, data in percentages were arcsine transformed (Sokal and Rohlf 1981).

General Linear Model Univariate procedure was used to test differences between slopes or intercepts of the different relations between inundation and established hawthorn or hawthorn growth. Non-linear relations were transformed in order to obtain linear relationships before testing differences between slopes or intercepts.

All data were analysed using SPSS for Windows version 23 (Norusis 1996). All error bars in graphs are Standard Errors of Means (SEM).

\section{Results}

\section{Herbivore numbers and DEE}

Horses grazed the area year-round in the same numbers every year: 20 mares. Cattle grazed the area from April until November in the same numbers every year: 15 cows. During the winters of 1997/1998, 1999/2000 and $2007 / 2008$, average rabbit numbers within the study area were respectively 35,25 and 90 . Almost nearly no hares were recorded (average $<1$ ).
During summer, DEE per day of the 35 large herbivores was about $1650 \mathrm{MJ}$ for the whole study area, and during winter DEE was about $950 \mathrm{MJ}$. DEE of rabbits varied between 20 and $70 \mathrm{MJ}$ for the whole study area. During winter, total DEE of mares was about 15-50 times higher than that of rabbits. As DEE of the large herbivores almost doubled during summer, the difference between large and small herbivores probably will have been even greater during that period.

\section{Established woody species}

The results of the survey in 2007 (Table 2) reflect the net effect of establishment and mortality and the net effect of growth and losses over 12 years. In general, there were fewer species of woody plants on the grasslands than on the excavated strata. Within the grasslands, there were no woody species at all on GH. On the excavated substrates, there were more thorny shrubs on EM and more Salix spp. on EL. Heights of woody species varied among strata and between grazed and ungrazed.

\section{Effects of rabbits}

Total number of hawthorn recorded in 2007 in the plots grazed by rabbits (Fig. 3) was not different from that in ungrazed plots $(\mathrm{P}=0.9882)$. Growth parameters of hawthorn in the plots grazed by rabbits were not different from those recorded in ungrazed plots (Fig. 5;

Table 2 Average cover and height of woody species in 2007. SEM is given in parentheses. $\mathrm{C}=$ cattle; $\mathrm{H}=$ horses; $\mathrm{R}=$ rabbits.

\begin{tabular}{|c|c|c|c|c|c|c|c|c|c|}
\hline \multicolumn{10}{|c|}{ Strata } \\
\hline \multirow{3}{*}{$\begin{array}{l}\text { Habitat } \\
\text { Ground level } \\
\text { Grazed/ungrazed } \\
\text { herbivores }\end{array}$} & \multicolumn{4}{|c|}{ Grassland } & \multicolumn{5}{|c|}{ Excavated } \\
\hline & \multicolumn{2}{|c|}{ High } & \multicolumn{2}{|c|}{ Medium high } & \multicolumn{2}{|c|}{ Medium high } & \multicolumn{3}{|c|}{ Low } \\
\hline & Ungrazed & $\begin{array}{c}\text { Grazed } \\
\text { CHR }\end{array}$ & Ungrazed & $\begin{array}{c}\text { Grazed } \\
\text { CHR }\end{array}$ & Ungrazed & $\begin{array}{c}\text { Grazed } \\
\text { CHR }\end{array}$ & Ungrazed & $\begin{array}{c}\text { Grazed } \\
\text { CHR }\end{array}$ & $\begin{array}{c}\text { Grazed } \\
\text { R }\end{array}$ \\
\hline Species & \multicolumn{9}{|c|}{ Cover $(\%)$} \\
\hline Crataegus monogyna & 0 & 0 & $5(5)$ & $2(1)$ & $15(6)$ & $2(1)$ & $3(2)$ & 0 & $3(2)$ \\
\hline Rosa canina & 0 & 0 & 0 & 0 & $9(6)$ & $7(3)$ & $1(<1)$ & 0 & $1(<1)$ \\
\hline Rubus ceasius & 0 & 0 & $19(18)$ & 0 & $7(3)$ & $1(1)$ & $4(<1)$ & 0 & $3(1)$ \\
\hline Cornus sanguinea & 0 & 0 & 0 & 0 & $<1(<1)$ & 0 & 0 & 0 & 0 \\
\hline Sorbus aucuparia & 0 & 0 & 0 & 0 & 0 & 0 & $<1(<1)$ & 0 & 0 \\
\hline Fraxinus excelsior & 0 & 0 & 0 & 0 & 0 & 0 & 0 & 0 & $<1(<1)$ \\
\hline Populus nigra & 0 & 0 & 0 & 0 & 0 & 0 & $<1(<1)$ & 0 & $1(1)$ \\
\hline Salix spp. & 0 & 0 & 0 & 0 & $10(5)$ & 0 & $40(15)$ & $3(1)$ & $32(9)$ \\
\hline \multirow[t]{2}{*}{ Total woody cover } & 0 & 0 & $21(20)$ & $2(2)$ & $28(9)$ & $9(3)$ & $43(16)$ & $3(1)$ & $34(11)$ \\
\hline & \multicolumn{9}{|c|}{ Height $(\mathrm{cm})$} \\
\hline Crataegus monogyna & & & $450(-)$ & $412(-)$ & $120(20)$ & $78(26)$ & $47(125)$ & & $77(27)$ \\
\hline Rosa canina & & & & & $150(29)$ & $147(29)$ & $83(13)$ & & 105(18) \\
\hline Rubus ceasius & & & $85(5)$ & & $37(13)$ & $20(-)$ & $53(12)$ & & $53(12)$ \\
\hline Cornus sanguinea & & & & & $65(-)$ & & & & \\
\hline Sorbus aucuparia & & & & & & & $60(-)$ & & \\
\hline Fraxinus excelsior & & & & & & & & & $20(-)$ \\
\hline Populus nigra & & & & & & & $390(-)$ & & $275(-)$ \\
\hline Salix spp. & & & & & $300(50)$ & & $483(17)$ & $12(2)$ & $427(18)$ \\
\hline
\end{tabular}


Table 3 P-values Generalized Linear Model with Poisson distribution and log-link for total number of established hawthorn in 2007. G = grazing (yes or no); $\mathrm{E}=$ elevation $(7.5 \mathrm{~m}$ or $6.0 \mathrm{~m}$ ) or excavation (yes or $\mathrm{no}$ ); $\mathrm{G} \times \mathrm{E}=$ interaction effect; Block was nested within the factor Elevation or Excavation to correct for possible random variation among blocks. The bold $p$-values highlight that the effects are significant.

\begin{tabular}{|c|c|c|c|c|c|}
\hline & \multirow{2}{*}{ G } & \multicolumn{2}{|c|}{$\mathbf{E}$} & \multirow{2}{*}{$\mathbf{G} \times \mathbf{E}$} & \multirow{2}{*}{ Block (E) } \\
\hline & & Ground level & Excavation & & \\
\hline Grassland 7.5 m vs Excavated 7.5 m & 0.0006 & & 0.0001 & 0.2344 & $<0.0001$ \\
\hline Excavated $7.5 \mathrm{~m}$ vs Excavated $6.0 \mathrm{~m}$ & $<0.0001$ & $<0.0001$ & & a & $<0.0001$ \\
\hline
\end{tabular}

a Unable to compute due to absence of hawthorn in grazed excavated $6.0 \mathrm{~m}$.

Table 4 P-values General Linear Model Repeated Measures for the effects of grazing and elevation or excavation on cover and height of low grasses and herbs and tall herbs. A, B and $\mathbf{C}$ show the results of the comparisons between different strata. Grazing = grazed or ungrazed by cattle, horses and rabbits. Elevation $=9.0 \mathrm{~m}$ vs $7.5 \mathrm{~m}$ or $7.5 \mathrm{~m}$ vs $6.0 \mathrm{~m}$. Excavation $=$ yes or no. Year $=1997,1999,2001,2007 . \mathbf{D}$ shows the results of the comparison between plots grazed by rabbits and ungrazed plots on the stratum excavated low.

\begin{tabular}{|c|c|c|c|c|}
\hline & \multicolumn{2}{|c|}{ Grasses and herbaceous plants } & \multicolumn{2}{|c|}{ Tall herbaceous plants } \\
\hline & Cover & Height & Cover & Height \\
\hline \multicolumn{5}{|c|}{ A. Grassland $9.0 \mathrm{~m}$ vs Grassland $7.5 \mathrm{~m}$} \\
\hline \multicolumn{5}{|l|}{ Test of Between-Subjects Effects } \\
\hline Grazing & 0.4770 & 0.0005 & 0.0170 & 0.0225 \\
\hline Ground level & 0.9207 & 0.4264 & 0.7119 & 0.2218 \\
\hline Grazing $x$ Ground level & 0.8899 & 0.2662 & 0.0267 & 0.4567 \\
\hline Block (within Ground level) & 0.7144 & 0.9951 & 0.2132 & 0.3905 \\
\hline \multicolumn{5}{|l|}{ Test of Within-Subjects Effect } \\
\hline Year & 0.0016 & $<0.0001$ & 0.0001 & $<0.0001$ \\
\hline Year x Grazing & $<0.0001$ & $<0.0001$ & 0.3875 & 0.0105 \\
\hline Year x Ground level & 0.9627 & 0.3046 & 0.0900 & 0.7185 \\
\hline Year x Grazing x Ground level & 0.8761 & 0.9555 & 0.6587 & 0.2826 \\
\hline \multicolumn{5}{|c|}{ B. Grassland 7.5 m vs Excavated 7.5 m } \\
\hline \multicolumn{5}{|l|}{ Test of Between-Subjects Effects } \\
\hline Grazing & 0.0495 & 0.0083 & 0.8015 & 0.0233 \\
\hline Ground level & 0.0065 & 0.0436 & 0.0262 & 0.0489 \\
\hline Grazing $\times$ Ground level & 0.1543 & 0.0318 & 0.5611 & 0.1062 \\
\hline Block (within Ground level) & 0.8496 & 0.9300 & 0.3488 & 0.4961 \\
\hline \multicolumn{5}{|l|}{ Test of Within-Subjects Effect } \\
\hline Year & $<0.0001$ & 0.1676 & 0.0060 & 0.0001 \\
\hline Year x Grazing & 0.0003 & 0.0241 & 0.7302 & 0.0324 \\
\hline Year x Ground level & 0.0002 & 0.0602 & 0.0023 & 0.1371 \\
\hline Year $x$ Grazing $x$ Excavation & 0.0022 & 0.0336 & 0.7909 & 0.6087 \\
\hline \multicolumn{5}{|c|}{ C. Excavated $7.5 \mathrm{~m}$ vs Excavated $6.0 \mathrm{~m}$} \\
\hline \multicolumn{5}{|l|}{ Test of Between-Subjects Effects } \\
\hline Grazing & 0.0174 & 0.3408 & 0.9297 & 0.0103 \\
\hline Ground level & 0.0087 & 0.0404 & 0.2063 & 0.0387 \\
\hline Grazing x Ground level & 0.4235 & 0.5569 & 0.3179 & 0.0577 \\
\hline Block (within Ground level) & 0.5449 & 0.9099 & 0.3378 & 0.4482 \\
\hline \multicolumn{5}{|l|}{ Test of Within-Subjects Effect } \\
\hline Year & $<0.0001$ & 0.7767 & 0.1837 & 0.0086 \\
\hline Year x Grazing & 0.1613 & 0.1971 & 0.4845 & 0.0734 \\
\hline Year x Ground level & 0.0057 & 0.8392 & 0.3483 & 0.2544 \\
\hline Year x Grazing x Ground level & 0.1359 & 0.4527 & 0.4091 & 0.0634 \\
\hline \multicolumn{5}{|c|}{ D. Excavated 6.0 m: Grazed by Rabbits vs Ungrazed } \\
\hline \multicolumn{5}{|l|}{ Test of Between-Subjects Effects } \\
\hline Grazing & 0.3669 & 0.6077 & 0.4586 & 0.0657 \\
\hline Block & 0.3889 & 0.9157 & 0.6732 & 0.0626 \\
\hline \multicolumn{5}{|l|}{ Test of Within-Subjects Effects } \\
\hline Year & 0.1503 & 0.0832 & 0.2286 & 0.1475 \\
\hline Year x Grazing & 0.3470 & 0.4698 & 0.1414 & 0.4078 \\
\hline
\end{tabular}

European Journal of Environmental Sciences, Vol. 9, No. 1 
Table 5 P-values General Linear Model Univariate for testing differences in slopes and intercepts of regression lines between strata and between grazed and ungrazed (see Fig. 5). $\mathrm{CHR}=$ cattle, horses and rabbits. $\mathrm{R}=$ rabbits. The bold $\mathrm{P}$-values highlight that the differences are significant.

\begin{tabular}{|l|c|c|c|c|c|c|}
\hline \multirow{2}{*}{} & \multicolumn{2}{|c|}{$\begin{array}{c}\text { Excavated medium high vs excavated } \\
\text { low for ungrazed CHR }\end{array}$} & \multicolumn{2}{|c|}{$\begin{array}{c}\text { Ungrazed CHR vs Grazed CHR } \\
\text { on excavated medium high }\end{array}$} & \multicolumn{2}{|c|}{$\begin{array}{c}\text { Ungrazed CHR vs Grazed R } \\
\text { on excavated low }\end{array}$} \\
\cline { 2 - 7 } & Slopes & Intercepts & Slopes & Intercepts & Slopes & Intercepts \\
\hline Height & 0.4633 & $<\mathbf{0 . 0 0 0 1}$ & 0.5355 & $\mathbf{0 . 0 1 5 9}$ & 0.8290 & 0.9007 \\
\hline Crown & 0.7795 & 0.7965 & 0.1495 & 0.4985 & 0.8167 & 0.2819 \\
\hline Stem & 0.1001 & 0.5687 & 0.4353 & 0.1097 & 0.2806 & 0.3595 \\
\hline Twigs & 0.6137 & 0.0771 & 0.2380 & 0.8725 & 0.7902 & 0.9641 \\
\hline
\end{tabular}

Table 5). Cover and height of low grasses and herbaceous plants and of tall herbaceous plants in plots grazed by rabbits (Fig. 6) were not different from that recorded in ungrazed plots (Table 4).

\section{Effects of excavation, inundation and large herbivore grazing}

The total number of hawthorn recorded over the period 1996-2007 was affected by herbivores and ground level or excavation and was highest on EM-u and absent on GH and EL-g (Fig. 3, Table 3). The years in which hawthorn were recorded differed among strata (Fig. 3). On GM, hawthorn were only present during the first three years. On EM, they were present almost throughout the whole period, but the highest numbers were recorded between 1998-2002. On EL-u, most were recorded between 2002-2005.

Establishment on the excavated strata was related to water level. In general, more hawthorn were recorded on the less inundated EM than on the more inundated EL, indicating a negative relation with inundation (Fig. 3, Table 3). However, if we look at the results in detail, numbers on EM was positively related to inundation whereas on EL it was negatively related (Fig. 4). In the grazed excavated strata, relationships were the same as in the ungrazed strata.

Of the growth parameters only height was affected (Fig. 5). On EM-u, shrubs were 50-100 cm shorter than on EL-u (comparison of the heights of the same age classes). On EM-u, shrubs were 25-50 cm taller than on EM-g.

Cover and height of the grass and herbaceous plant layers differed between strata, years and between grazed and ungrazed sites (Fig. 6; Table 4). The cover of low grasses and herbaceous plants decreased in the grasslands and increased on the excavated strata. On the grasslands, the decrease in cover was greater at the ungrazed than at the grazed sites. On the excavated strata, the increase in cover was lower at the ungrazed than at the grazed sites. The height of the low grasses and herbaceous plants was greater in the grasslands than in the excavated strata and also greater at ungrazed than at grazed sites.

The cover and height of tall herbaceous plants increased strongly on the grasslands. On the excavated strata, cover was stable and height increased.

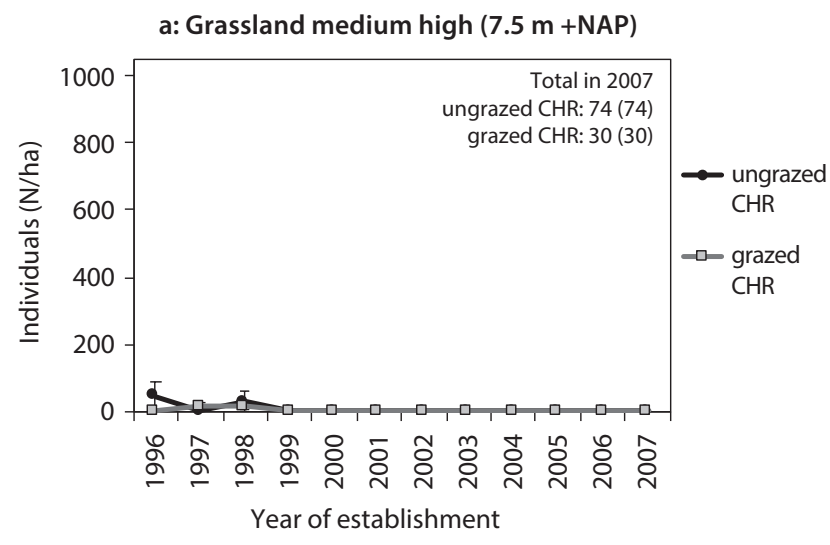

b: Excavated medium high (7.5 m +NAP)
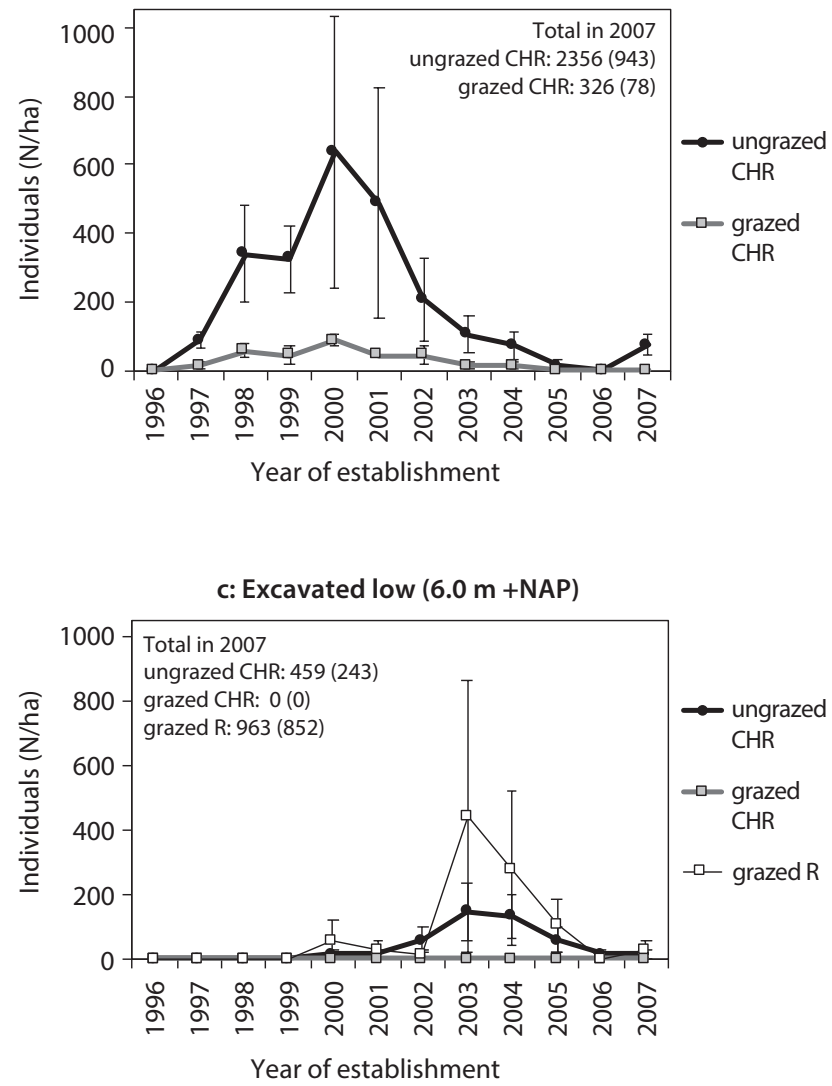

Fig. 3 Number of hawthorn recorded on different strata in different years. $\mathrm{C}=$ cattle, $\mathrm{H}=$ horses, $\mathrm{R}=$ rabbits. In the corner of the graphs the average number of hawthorn recorded over the period 1996-2007, is given; SEM within parentheses. 

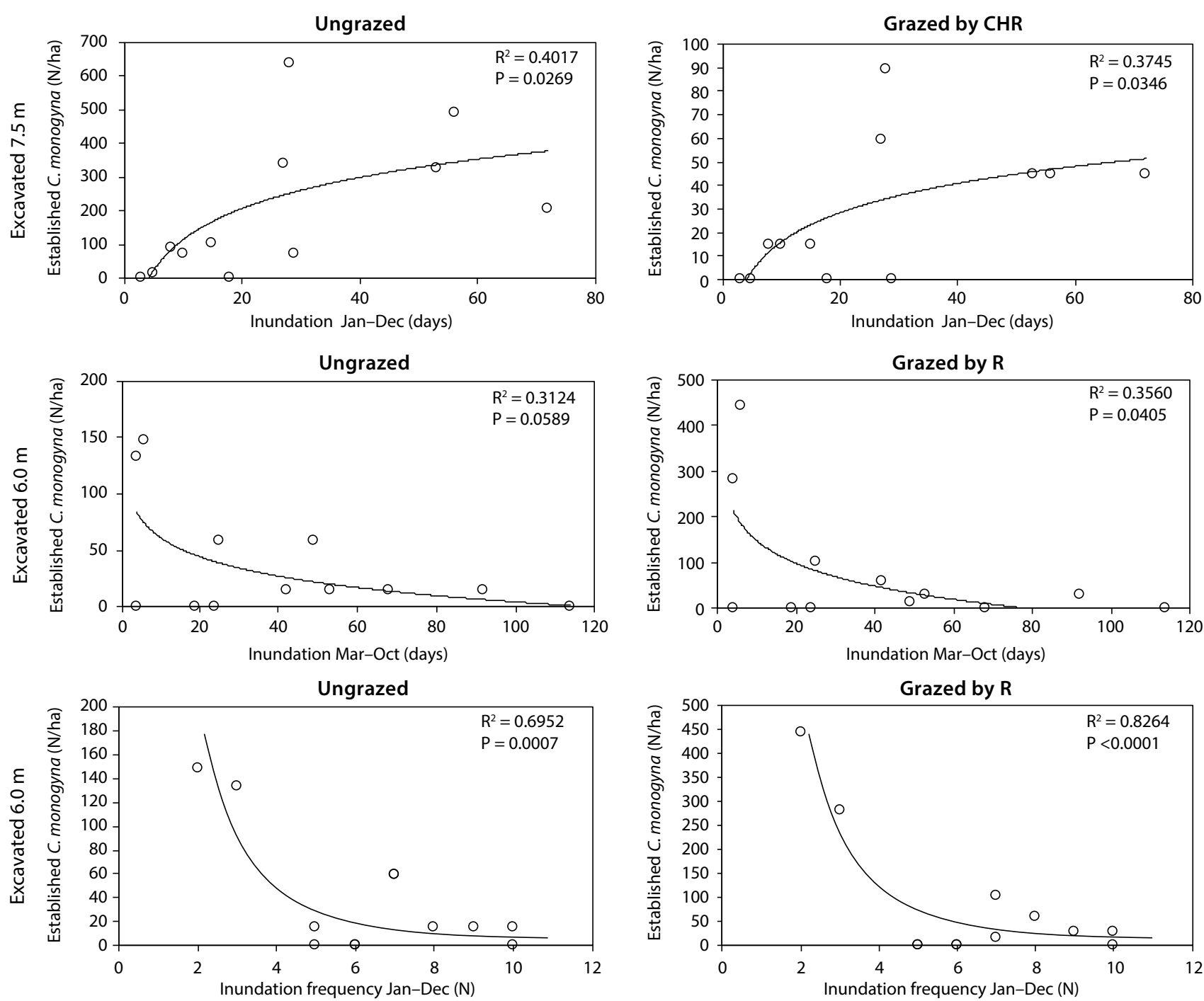

Fig. 4 Relations between inundation and establishment of hawthorn (top and middle) and between inundation frequency and establishment of hawthorn (bottom) on ungrazed and grazed strata. Establishment of hawthorn during the period 1996-2007. C $=$ cattle, $\mathrm{H}=\mathrm{horses}, \mathrm{R}=\mathrm{rabbits}$. Note differences in $\mathrm{Y}$ - and $\mathrm{X}$-axes.

\section{Discussion}

\section{Effects of excavation}

This study revealed that in the excavated areas of the floodplain there was a greater establishment of hawthorn than in the non-excavated grasslands, which supports our first expectation. There were also more other woody species present on the excavated areas than on the grasslands. After excavation, bare substrate was exposed over large areas for a few years, as the fertile soil layer was removed. The development of tall herbaceous vegetation was much less than in the grasslands, providing more opportunities for the establishment of hawthorn and other woody species. Similar effects of vegetation cover on the establishment of woody species are reported in other studies (e.g. Siebel 1998; Bokdam and Gleichman 2000; Niinemets and Valladares 2006). In the non-excavated grasslands, the woody seedlings have to compete with tall herbaceous plants such as $C$. arvense and $U$. dioica for light and nutrients. These fast growing tall herbaceous plants are stronger competitors than the seedlings of woody species in highly productive environments, such as the grasslands on clayey soils. We conclude that the tall herbaceous vegetation played an important role in the establishment of hawthorn and the other woody species.

This detailed study of hawthorn revealed that more shrubs established on EM than on EL. This supports our second expectation that establishment is negatively affected by inundation. However, when the results are examined in more detail, the negative relation was true for the EL sites, but not for the EM sites, where the relation was positive. We assume that on EL and during periods of high water level, inundation was sufficiently frequent, to prevent seeds from germinating and seedlings becoming established as frequent inundation results in the seedlings due to drowning or oxygen deprivation (Niinemets and Valladares 2006; Vreugdenhil et al. 2006). Only during periods with relatively low water levels (2003-2007), hawthorn colonized and survived on EL. The less frequent inundation of EM probably resulted in the high- 

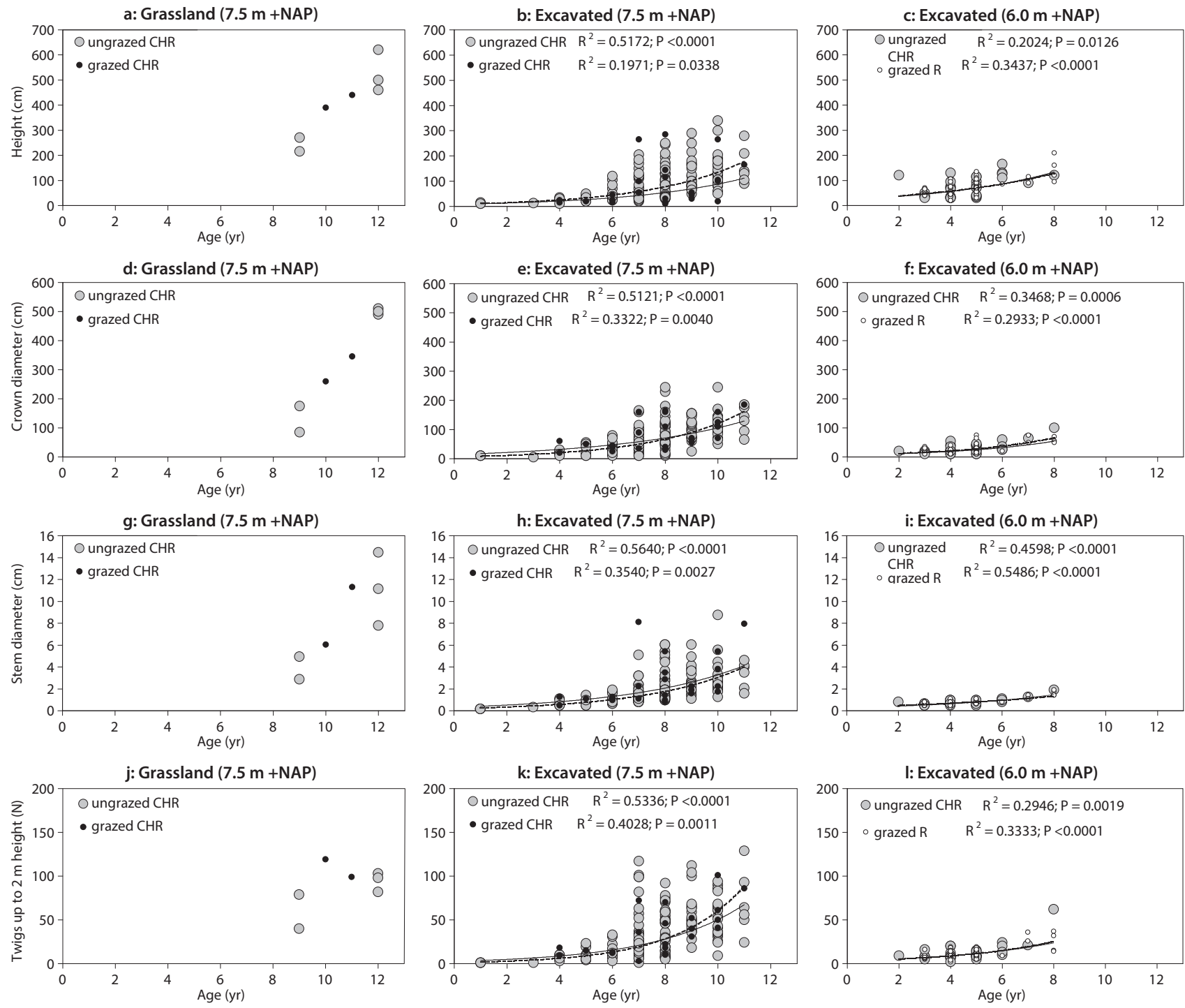

Fig. 5 Height $(A-C)$, crown diameter $(D-F)$, stem diameter $(G-I)$ and number of twigs $(J-L)$ of hawthorn of different ages growing on different strata and in grazed and ungrazed situations. $\mathrm{C}=$ cattle, $\mathrm{H}=$ horses, $\mathrm{R}=$ rabbits. Within the graphs $\mathrm{R}^{2}$ and $\mathrm{P}$-values are given for the relations. See table $\mathrm{A}$ (below) for results of the tests for differences between relations.

er survival of hawthorn there than on EL, but this does not explain the positive relation between inundation and establishment. A potential explanation of this positive relation could be fruit dispersal by water. During field observations (pers. obs. P. Cornelissen), fruit were found in drift line material. As fruit of hawthorn can also be dispersed by water, lower water levels can lead to less or no seed deposition by water on the higher ground. Although hawthorn fruit can also be dispersed by wind (very short distances), birds and mammals (short and long distances; Good et al. 1990; Martinez et al. 2008), only water can disperse large amounts of fruit over long distances.

On GM, a similar positive relation between inundation and seed deposition exists. The effect, however, is different from that on EM. The difference may be explained by the greater increase in cover and height of tall herbaceous plants on the grasslands than at the excavated sites.

Inundation also affected the height of hawthorn. Our results indicate that height was greater on EL than on EM (comparison of the same age classes of low and medium height in Fig. 5). This could be explained by shoot elongation to overcome flooding events. This is demonstrated by Siebel (1998), where partially submerged seedlings of Q. robur and Fraxinus excelsior L. showed a significantly larger increase in stem length than unflooded ones. Probably, hawthorn uses the same mechanism to survive inundation.

\section{Effects of grazing}

On EL, rabbits did not affect the establishment and growth of hawthorn, and the cover and height of grasses and herbaceous plants. Therefore, we conclude that the described effects of herbivores on the establishment and growth of hawthorn were caused by cattle and horses, supporting the third expectation. Bakker et al. (2004) report that the negative effect of rabbits on woody species equals that of cattle. However, in their study area, DEE of rabbits equalled that of cattle, whereas in our study area 


\section{a: Cover low grasses and herbs}

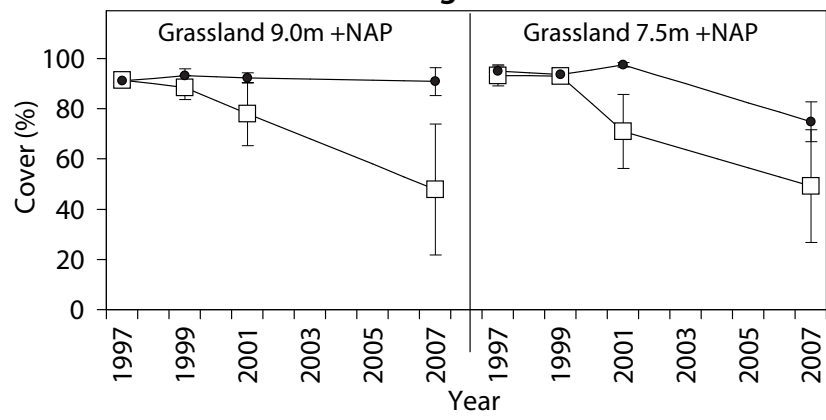

c: Height low grasses and herbs

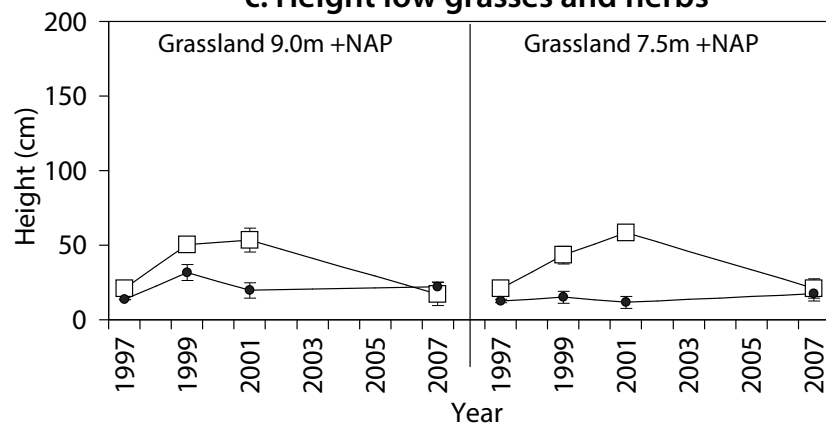

e: Cover tall herbs

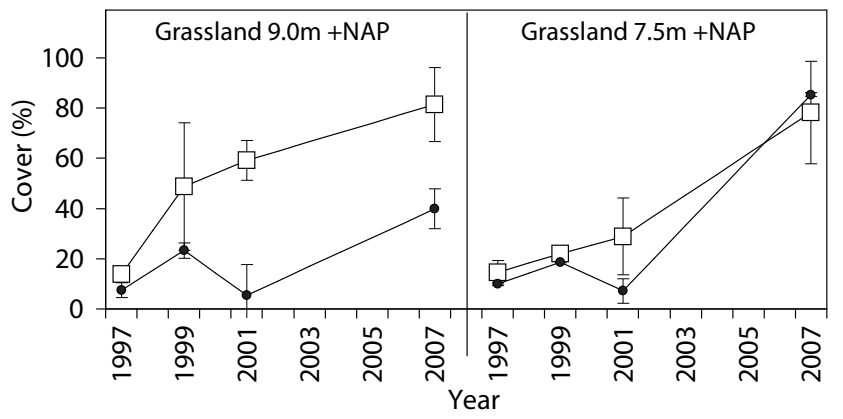

g: Height tall herbs

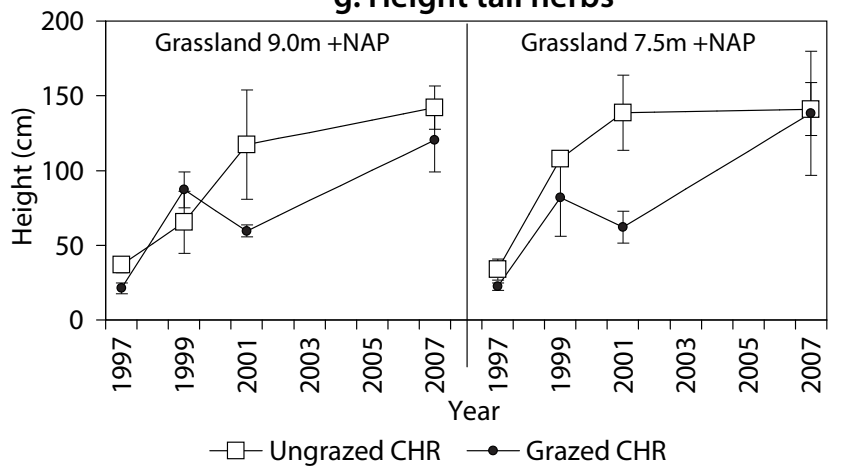

b: Cover low grasses and herbs

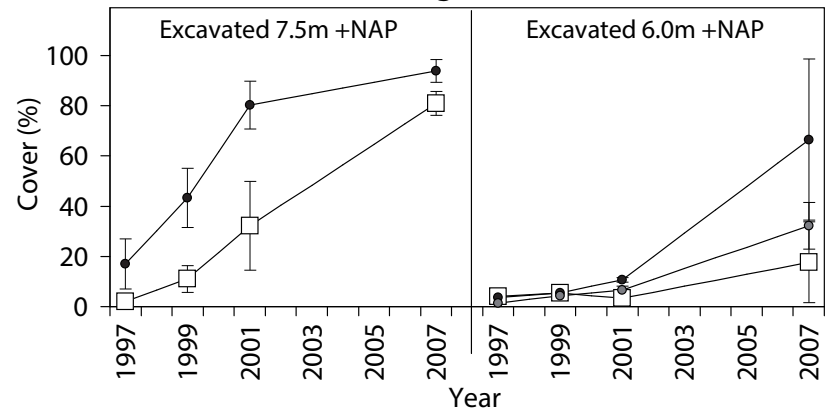

d: Height low grasses and herbs

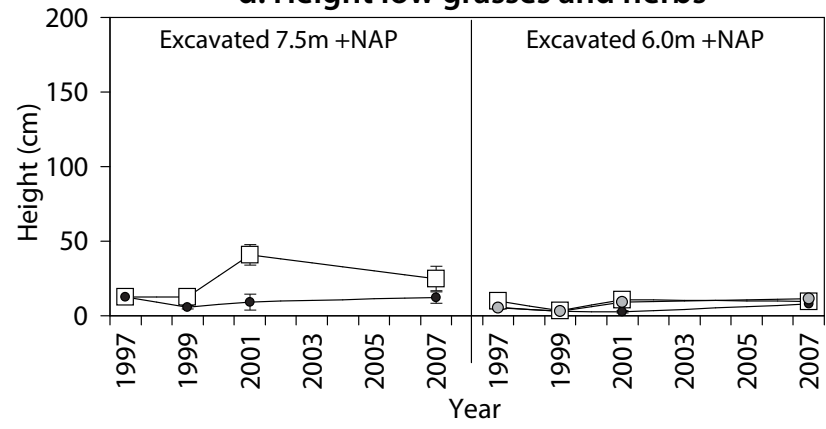

f: Cover tall herbs

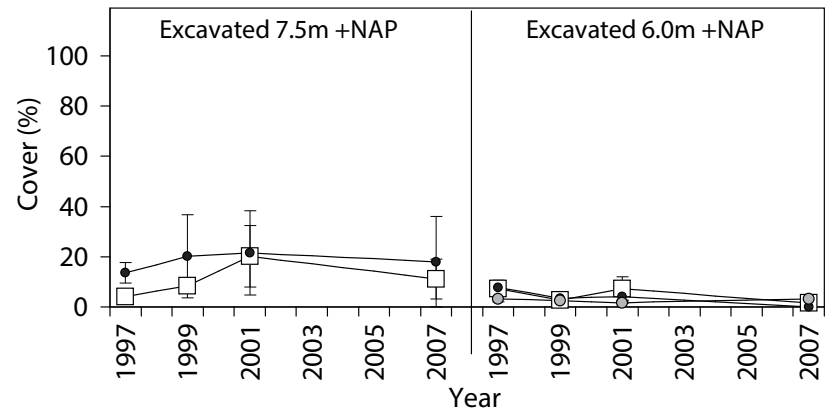

h: Height tall herbs

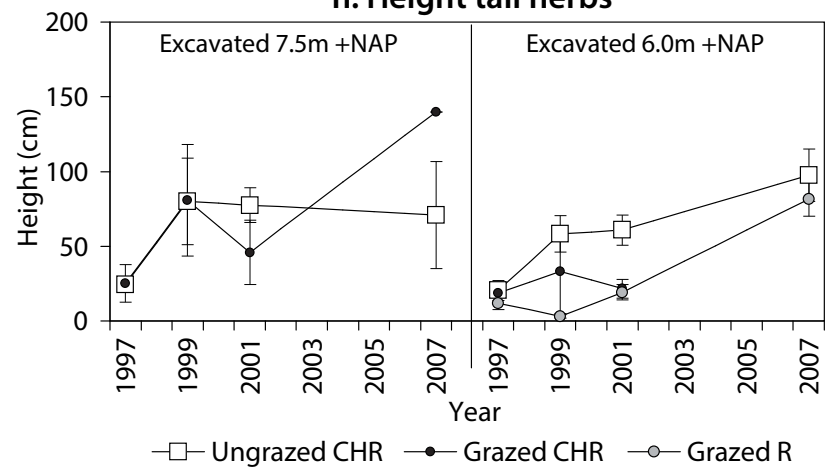

Fig. 6 Development of cover and height of the structural layers "low grasses and herbaceous plants" and "tall herbaceous plants" on different strata and in grazed and ungrazed situations. $\mathrm{C}=$ cattle, $\mathrm{H}=$ horses, $\mathrm{R}=$ rabbits.

DEE of rabbits was $>15$ times lower than that of cattle and horses during winter. Kuiters and Slim (2003) report significant effects of rabbits on tree regeneration only at very high densities of 50 rabbits per ha, which is about 25 times higher than recorded in our study area.

On the grasslands, there were too few plants of hawthorn to test our fourth expectation. According to the wood-pasture theory (Vera 2000), large herbivores play a key role in the development of park-like landscapes with shrub and tree regeneration in the grazed grasslands.
Vera (2000) and Olff et al. (1999) also mention that the intensively grazed grasslands in the woodland-grassland cycle need a temporary reduction in the large herbivore population densities in order to create a "window of opportunity" for the (re-)establishment of shrubs and trees. In our study area, the change in grazing management in 1996 from intensively to extensively grazed, could have been the reason why hawthorn successfully colonized medium high grassland during the first three years of the research period, when cover and height of tall herbaceous 
plants were still low. In the ungrazed plots after 1998, the cover of tall herbaceous plants had already increased by more than $20 \%$ with heights exceeding $1 \mathrm{~m}$. Apparently, this was enough to prevent the establishment of hawthorn and other woody shrubs and trees. In the grazed plots, the cover and height of tall herbaceous plants decreased again in 2001, but this did not result in new establishments of hawthorn, or other woody species, in the grazed plots. This could be due to the fact that within the grazed sites, there were locations where tall herbaceous plant dominated and out competed the hawthorn seedlings for light, whereas at the locations where low grasses and herbaceous plants dominated, local grazing pressure was too high, indicated by the low height of the grasses and herbaceous plants, for the hawthorn seedling to survive. The fact that there were no woody species on GH was probably due to a faster increase in cover and height of the tall herbaceous plant layer and absence of a large input seed carried by water (for example hawthorn) during the first years compared with GM.

\section{Implications for management}

This study confirmed that excavation, which increases the discharge capacity of the floodplain, also increased opportunities for shrub and tree regeneration and floodplain forest development. For safety purposes, it is necessary to control the growth of woody species as shrubs and trees can seriously obstruct water flow and reduce the discharge capacity of the river. Our research shows that large herbivores can control the encroachment by woody plants, but much depends on the management of the grazing regime. Although there was a strong negative effect on establishment of hawthorn, the numbers of cattle and horses were insufficient for stopping the development or reducing the growth of this shrub. To suppress hawthorn, more animals and types of herbivores (grazers, intermediate feeders and browsers; large and small herbivores) are needed (e.g. Good et al. 1990; Williams et al. 2010; Cornelissen et al. 2014a).

It is possible to reduce the encroachment of floodplains by woody plants by minimizing their establishment and growth. First of all, it is possible to reduce the areas with ground levels that favour the establishment of shrubs and trees. Another possible measure is to recover excavated areas with the top layer of soil that was removed. This will enhance a rapid recovery of the grass and herbaceous plant layer, diminish the opportunities for the establishment and growth of woody species. A third option is to periodically lower large areas of the floodplain or dig side channels to increase the flow capacity of the floodplain so that a larger area of forest is acceptable. This measure is also known as the "cyclic floodplain rejuvenation" (Baptist et al. 2004). Finally, grazing regimes can be introduced that are more likely to control the development of woody plants. An assemblage of different kinds of herbivores with greater numbers of cattle and horses ( $>1$ animal per ha), more intermediate feeders (e.g. red deer), browsers (e.g. roe deer) and small herbivores (beavers, rabbits and hares) will stimulate browsing. Preferentially, these grazing regimes should start immediately after excavation in order to control establishment for several years, or at least until vegetation cover has developed to a sufficient level.

For rehabilitation of natural floodplain forests, lowering the floodplain and digging side channels are ideal measures for regenerating shrubs and trees in grazed systems. Our research showed that high numbers of hawthorn, a key species in the wood-pasture hypothesis (Vera 2000), can become established and create opportunities for the establishment of palatable and less protected hardwood tree species (Barbosa et al. 2009) and initiate floodplain forest development in these extensively grazed areas.

\section{Acknowledgements}

We would like to thank Staatsbosbeheer (State Forestry Service) for giving us permission to use their protected area to carry out this research. We wish to thank Jaap Daling, Menno Zijlstra and Moniek Bestman for assisting in collection of the data. Two anonymous reviewers and Gera van Os provided useful comments on an earlier draft. The language editor was Stanford Wilson.

\section{REFERENCES}

Bakker ES, Olff H, Boekhoff M, Gleichman JM, Berendse F (2004) Impact of herbivores on nitrogen cycling: contrasting effects of small and large species. Oecologia 138: 91-101.

Baptist MJ, Penning WE, Duel H, Smits AJM, Geerling GW, VanderLee GEM, VanAlphen JSL (2004) Assessment of the effects of cyclic floodplain rejuvenation on flood levels and biodiversity along the Rhine river. River Res Appl 20: 285-297.

Baraza E, Zamora R, Hódar A (2006) Conditional outcomes in plant-herbivore interactions: Neighbours matter. Oikos 113: 148-156.

Barbosa P, Hines J, Kaplan I, Martinson H, Szezepaniec A, Szendrei Z (2009) Associational resistance and associational susceptibility: Having right or wrong neighbours. Ann Rev Ecol Evol Syst 40: 1-20.

Bokdam J, Gleichman JM (2000) Effects of grazing by free-ranging cattle on vegetation dynamics in a continental north-west European heathland. J Appl Ecol 37: 415-431.

Brown AG, Harper D, Peterken GF (1997) European floodplain forests: structure, functioning and management. Global Ecol Biogeogr Letters 6: 169-178.

Bunting DP, Papuga S, Grabau M (2013) Long-term vegetation dynamics after high-density seedling establishment: Implications for riparian restoration and management. River Res Appl 29: 1119-1130.

Buttenschøn J, Buttenschøn RM (1985) Grazing experiments with cattle and sheep on nutrient poor, acidic grassland and heath. IV: establishment of woody species. Natura Jutlandica 21: 47-140.

Cornelissen P, VanDeursen EJM, Vulink JT (1995) Year-round grazing at the Zoutkamperplaat: Effects on vegetation and per- 
formance of cattle and horses (in Dutch). Ministry of Transport and Public Works. Lelystad, the Netherlands.

Cornelissen P, Gresnigt MC, Vermeulen R, Bokdam J, Smit R (2014a) Transition of a Sambucus nigra L. dominated vegetation into grassland by a multi-species herbivore assemblage. J Nat Conserv 22: 84-92.

Cornelissen P, Bokdam J, Sykora K, Berendse F (2014b) Effects of large herbivores on wood pasture dynamics in a European wetland system. Basic Appl Ecol 15: 396-406.

Decuyper M, Cornelissen P, Sass-Klaassen U (2014) Establishment and growth of hawthorn in floodplains in the Netherlands. Dendrochronologia 32: 173-180.

DeWaal LC, Large ARG, Gippel CJ, Wade PM (1995) River floodplain rehabilitation in Western Europe: opportunities and constraints. Archive für Hydrobiologie 101: 679-693.

Dynesius M, Nilsson C (1994) Fragmentation and flow regulation of river systems in the northern third of the world. Science 266 : 753-762.

Garcia D, Chacoff NP (2007) Scale-dependent effects of habitat fragmentation on Hawthorn pollination, frugivory, and seed predation. Conserv Biol 21: 400-411.

Gill R (2006) The influence of large herbivores on tree recruitment and forest dynamics. In: Danell K, Bergström R, Duncan P, Pastor J (eds) Large herbivore ecology, ecosystem dynamics and conservation. Cambridge University Press. Cambridge, UK, pp 170-202.

Good JEG, Bryant R, Carlill P (1990) Distribution, longevity and survival of upland hawthorn (Crataegus monogyna) scrub in North Wales in relation to sheep grazing. J Appl Ecol 27: 272283.

Herrera CM (1984) Seed dispersal and fitness determinants in wild roses. Combined effects of hawthorn, birds, mice, and browsing ungulates. Oecologia 63: 386-393.

Hester AJ, Bergman M, Iason GR, Moen J (2006) Impacts of large herbivores on plant community structure and dynamics. In: Danell K, Bergström R, Duncan P, Pastor J (eds) Large herbivore ecology, ecosystem dynamics and conservation. Cambridge University Press. Cambridge, UK, pp 97-141.

Hughes FMR, Adams WM, Muller E, Nilsson C, Richards KS, Barsoum N, Decamps H, Foussadier R, Girel J, Guilloy H, Hayes A, Johansson M, Lambs L, Pautou G, Peiry J-L, Perrow M, Vautier F, Winfield M (2001) The importance of different scale processes for the restoration of floodplain woodlands. Regulated Rivers: Res Manag 17: 325-345.

Hurlbert SH (1984) Pseudoreplication and the design of ecological field experiments. Ecol Monogr 54: 187-211.

Jones RH, Sharitz RR, McLeod KW (1989) Effects of flooding and root competition on growth of shaded bottom land hard wood seedlings. Am Midl Nat 121: 165-175.

Kuiters AT, Hazebroek E, Hennekens M (2003) Actualized overview of grazed nature conservation areas in the Netherlands (in Dutch). Natuurbeheer 6: 79-82.

Kuiters AT, Slim PA (2003) Tree colonization of abandoned arable land after 27 years of horse-grazing: the role of bramble as a facilitator of oak wood regeneration. For Ecol Manag 181: 239-251.

Lange R, Twisk P, VanWinden A, VanDiepenbeek A (1994) Mammals of Western Europe (in Dutch). KNNV. Utrecht, the Netherlands.

Leyer I, Mosner E, Lehmann B (2012) Managing floodplain-forest restoration in European river landscapes combining ecological and flood-protection issues. Ecol Appl 22: 240-249.

Makaske B, Maas GJ, VandenBrink C, Wolfert HP (2011) The influence of floodplain vegetation on hydraulic roughness: is eco- system rehabilitation in Dutch embanked floodplains compatible with flood safety standards? Ambio 40: 370-376.

Martinez I, Garcia D, Obeso JR (2008) Differential seed dispersal patterns generated by a common assemblage of vertebrate frugivores in three fleshy-fruited trees. Ecoscience 15: 189-199. Naiman RJ, Décamps H (1997) The ecology of interfaces: The riparian zone. Ann Rev Ecol Syst 28: 621-658.

Naiman RJ, Bunn SE, Nilsson C, Petts GE, Pinay G, Thompson LC (2002) Legitimizing fluvial ecosystems as users of water. Environ Manag 30: 455-467.

Niinemets U, Valladares F (2006) Tolerance to shade, drought, and water logging of temperate Northern Hemisphere trees and shrubs. Ecol Monogr 76: 521-547.

Norusius MJ (2006) SPSS for windows. SPSS Inc. Chicago, USA.

Olff H, Vera FWM, Bokdam J, Bakker ES, Gleichman JM, de Maeyer K, Smit R (1999) Shifting mosaics in grazed woodlands driven by the alternation of plant facilitation and competition. Plant Biol 1: 127-137.

Olson DM, Dinerstein E (1998) The global 200: a representation approach to conserving the earth's most biologically valuable ecosystems. Conserv Biol 12: 501-512.

Rosenberg DM, McCully P, Pringle CM (2000) Global-scale environmental effects of hydrological alterations: Introduction. Bioscience 50: 746-751.

Siebel HN (1998) Floodplain forest restoration. Tree seedling establishment and tall herb interference in relation to flooding and shading. PhD Thesis, Nijmegen University the Netherlands.

Smith CJ (1980) Ecology of the English chalk. Academic Press. London, UK.

Snow B, Snow D (1988) Birds and Berries. A study of an ecological interaction. A\&C Black Publishers Ltd. London, UK.

Sokal RR, Rohlf FJ (1981) Biometry. The principles and practice of statistics in biological research (2nd ed.). W.H. Freeman and Company. New York, USA.

Streng DR, Glitzerstein JS, Hardcombe PA (1989) Woody seedling dynamics in an East Texas Floodplain forest. Ecol Monogr 59: 177-204.

Tockner K, Stanford JA (2002) Riverine flood plains: present state and future trends. Environ Conserv 29: 308-330.

Van der Meijden R (2005) Flora of the Netherlands (23rd ed.; in Dutch). Wolters-Noordhof. Groningen, the Netherlands.

Van Splunder I (1998) Floodplain forest recovery. Softwood forest development in relation to hydrology, riverbank morphology and management. PhD Thesis, Nijmegen University the Netherlands.

Van Velzen EH, Jesse P, Cornelissen P, Coops H (2003) Water resistance of vegetation in floodplains (in Dutch). Ministry of Transport and Public Works. RIZA report nr. 2003.028. Lelystad, the Netherlands.

Vera FWM (2000) Grazing ecology and forest history. CAB International. Wallingford, UK.

Vreugdenhil SJ, Kramer K, Pelsma T (2006) Effects of flooding duration, frequency and depth on the presence of saplings of six woody species in north-west Europe. For Ecol Manag 236: 47-55.

Watt AS (1934) The vegetation of the Chiltern Hills with special reference to the beechwoods and their seral relationships. Part II. J Ecol 22: 445-507.

Wallage-Drees JM (1988) Rabbits in the coastal sand dunes; weighed and counted. PhD Thesis, Leiden University the Netherlands.

Williams PA, Kean JM, Buxton RP (2010) Multiple factors determine the rate of increase of an invading non-native tree in New Zealand. Biol Invasions 12: 1377-1388. 